\title{
Clonidine Plus GHRH Administration for Diagnosing Growth Hormone Deficiency in Children
}

\section{Jesús Devesa}

Department of Physiology, Specialist in Endocrinology, Scientific Director of Medical Center Foltra, Spain

Corresponding author: Devesa J, Scientific Direction, Medical Center Foltra, Travesía de Montouto 24, 15886-TEO, Spain, Tel: +34 981802928; Email: jesus.devesa@usc.es

Rec date: April 15, 2017; Acc date: April 18, 2017; Pub date: April 21, 2017

Copyright: (c) 2017 Devesa J. This is an open-access article distributed under the terms of the Creative Commons Attribution License, which permits unrestricted use, distribution, and reproduction in any medium, provided the original author and source are credited.

Citation: Devesa J (2017) Clonidine plus GHRH Administration for Diagnosing Growth Hormone Deficiency in Children. J Clin Mol Endocrinol 2: 6

\section{Abstract}

Objective: To analyze the effectiveness and reproductivity of a challenge with clonidine (CLO) plus GHRH administration to establish a state of GH-deficiency and the causes of it.

Methods: 24 children (17M, 7F) with stature $<1$ or 2 SD from P3, previously studied with different classical tests, were given CLO $\left(150 \mu \mathrm{g} / \mathrm{m} 2\right.$ orally, at time $\left.0^{\prime}\right)$ plus GHRH $\left(60^{\prime}\right.$ later, $1 \mu \mathrm{g} / \mathrm{kg}$, iv). This test was repeated but giving placebo at time $0^{\prime}$. For comparison purposes, 20 agematched normal children (14M, 6F) were studied. Growth velocity (GV) and bone age (BA) before performing CLO + GHRH were considered.

Results: While classical GH tests show a great variability of negative or positive $\mathrm{GH}$ responses in the same short patient, all but two patients significantly responded to $\mathrm{CLO}+\mathrm{GHRH}$ (GH peak: $42.2 \pm 19$ vs. $41.6 \pm 3.5$ in controls). Controls showed a significant positive correlation between the amplitude of $\mathrm{GH}$ response and chronological and bone age ( $R=0.832 ; \mathrm{F}=37.6 ; \mathrm{P}=0.001$, multiple regression analysis): $\mathrm{y}=\mathrm{a}+\mathrm{b} \times \mathrm{BA}+\mathrm{c} \times \mathrm{CA}$, where $\mathrm{y}=\mathrm{GH}$ peak, $\mathrm{BA}=$ bone age, $\mathrm{CA}=$ chronological age, and $\mathrm{a}, \mathrm{b}$ and $\mathrm{c}$ are constants. This equation allows to establish the value of $\mathrm{GH}$ peak theoretically obtained after $\mathrm{CLO}+\mathrm{GHRH}$ challenge in a normal child. Applying this equation to the responses to CLO+GHRH in short children a deviation, ranging between $-435 \%$ and $+41 \%$, was obtained between theoretical and real GH peaks (\%DT-R). Responses between $-20 \%$ to $+20 \%$ were considered normal. Plotting these responses (\% DT-R) against the SD of the mean of the BA to GV ratio in normal children, five populations were defined: 1) Low response and low GV for BA; 2) Low response and normal GV for BA; 3) Normal response and low GV for BA; 4) Normal response and normal GV for BA; and 5) High response and low GV for BA.

Conclusion: The test CLO+GHRH is safe, effective and unique to detect $\mathrm{GH}$-deficiency and its causes in short children and adults.
Keywords: Growth hormone; Clonidine; Growth hormone releasing hormone; Growth hormone-deficiency; IGF-I; Bone age; Hypothalamic-somatotroph rhythm.

\section{Introduction}

Since the discovery in 1982 of growth hormone releasing hormone (GHRH) by Vale et al. [1] and Guillemin et al. [2], and the availability of this peptide, a number of studies demostrated that it was a specific inducer of GH secretion in man. On this basis it was tried to establish its utility as a diagnostic useful tool for clearly defining when a child was GH-deficient (GHD), and even more it was thought that this peptide would allow to define whether the deficiency of $\mathrm{GH}$ secretion occurred as a consequence of an hypothalamic dysfunction, or affectation, or it has its origin at the pituitary level [3-6]. Moreover, it was thought that in the cases of GHD due to a hypothalamic dysfunction the administration of GHRH might replace the treatment with GH [7-9].

However, physiologically, pituitary GH secretion is mainly subjected to a negative control exerted by somatostatin (SS), released from the hypothalamus into the portal blood; SS also negatively regulates hypothalamic GHRH secretion. Therefore, only when there is a physiological interruption of SS secretion, GHRH may be released and act on the pituitary synthesis and release of $\mathrm{GH}[10,11]$.

We demonstrated the existence of an endogenous hypothalamic-somatotroph rhythm (HSR) in man [12], responsible for the high variability in the $\mathrm{GH}$ responses to a GHRH test, even in the same individual tested at different daytimes.

According to our postulate, the administration of GHRH during a refractory phase of HSR, would not induce a significant $\mathrm{GH}$ response $(\mathrm{GH}$ peak $<10 \mathrm{ng} / \mathrm{ml})$, since during this phase hypothalamic SS would be physiologically released, therefore blocking the effect of GHRH on somatotrophs. This is the main reason by which most of GHRH tests carried out for analyzing whether $\mathrm{GH}$-deficiency exists in short stature children may give false negative results. In that study we demonstrated the need of taking into account plasma $\mathrm{GH}$ values $(-30,-15,0$ minutes) 
prior to GHRH challenge for knowing the HSR phase at which the test was performed and hence avoiding erroneous interpretation of the results obtained [12]. Most likely the lack of consideration of this concept led to GHRH being discontinued as a single test for analyzing $\mathrm{GH}$-deficiency.

Clinically, the finding of a test that would allow to clearly defining when $\mathrm{GH}$-deficiency exists and the origin of it would be very useful. Moreover, this putative test would also allow to decide when a treatment with $\mathrm{GH}$ is absolutely necessary and when this treatment should start. Many tests for analyzing $\mathrm{GH}$ secretion have been developed (propranolol plus exercise, levodopa, arginine, glucagon, insulin hypoglycemia, etc) [13-16], but perhaps because of the complexity of the mechanisms involved in $\mathrm{GH}$ neuroregulation, still they are controversed; mainly because of the lack of reproductibility, but also because most of them can not differentiate whether there is a pituitary affectation leading to insufficient or deficient $\mathrm{GH}$ secretion, or the affectation is due to a hypothalamic dysfunction. In addition, these classical tests are not able to differentiate between a neurosecretory dysfunction (transient or chronic), or when there is a Constitutional Growth Delay or Short Family stature, especially when Short Family stature is associated to a genetic reason. In addition, some of them may imply risks for the health of the child being analyzed, as it happens with the hypoglycemia induced by insulin (specially contraindicated in children with brain injuries, epilepsy or ischemic cardiopathy) since glycemia has to decrease about to $40 \mathrm{mg} / \mathrm{dl}$ for achieving a clear result in terms of $\mathrm{GH}$ response. In fact, some deaths occurred during this test, and recently we knew that the test had to be early interrupted since glycemia was as low as $20 \mathrm{mg} / \mathrm{dl}$.

As stated above, it was thought that GHRH would be very useful to establish and characterize $\mathrm{GH}$-deficient states. However, it was not happened; in general, and regardless of the etiology of GH-deficiency, most of the patients tested with GHRH showed a GH response to this stimulation [17]. Perhaps this was due to the fact that a hypothalamic dysfunction (absence or inadequated GHRH secretion into the portal blood) is the responsible reason for the lack of a physiological spontaneous $\mathrm{GH}$ release. On the other hand, subjects which did not respond to GHRH test could have been challenged during a refractory phase of the hypothalamic somatotroh rhythm [12], not taken into account when analyzing the $\mathrm{GH}$ responses to GHRH. This can occur either physiologically (normal trough period), or pathologically if there is a chronically increased somatostatinergic tone. Therefore, the lack of utility of GHRH as a tool for analyzing whether $\mathrm{GH}$-deficiency exists led to discard its use for this purpose.

Hypothalamic somatostatin release is negatively controlled by adrenergic and cholinergic pathways $[10,11]$. Therefore, the administration of alpha2-adrenergic agonists such as clonidine (CLO) will reduce, or impede, somatostatin secretion, allowing pituitary GH release to be enhanced [18-20]. The same occurs with the cholinergic agonist pyridostigmine [21], or galanin, which acting through the cholinergic pathways increases the $\mathrm{GH}$ response to GHRH in normal man [22,23]. On this basis it was postulated that the test Pyridostigmine plus GHRH would allow establishing and differentiating a deficient $\mathrm{GH}$ secretion of pituitary origin from one due to a hypothalamic dysfunction [24], without establishing whether there could exist a Congenital Delay of Growth or Short Family stature. Moreover, the fact that alpha2-adrenergic receptor blockade is able to blunt the increased response to pyridostigmine plus GHRH [25] indicates that this Pyridostigmine plus GHRH test may lead to false negative responses (indicating a false state of $\mathrm{GH}$-deficiency). On the contrary, pre-treatment with CLO increases the $\mathrm{GH}$ response to GHRH in short and normal children and also in adults $[18,26]$, but it was not known whether such a test could provide a differential diagnosis, and even treatment, of the diverse situations of GH-deficiency, or insufficiency in children.

In 1993, we tried to give an answer to the issues raised above performing a study, in which we compared the $\mathrm{GH}$ responses to the combined administration of CLO plus GHRH in children with stature below P3 (previously studied for GHD with other tests), with those obtained after this CLO plus GHRH stimulation in a population of normal children, matched in age and sex. Our data indicated that the $\mathrm{CLO}+\mathrm{GHRH}$ test is the most powerful test for establishing when a GHD exists and the causes leading to it.

\section{Patients and Methods}

\section{Short stature children}

24 children (17 boys and 7 girls, aged 7 to 13.9 years) with stature below one or two standard deviations from the third percentile (P3), participated in the study after obtaining signed informed consent from their parents or their legal representatives. The procedures used were in accordance with the guidelines of the Helsinki Declaration of human experimentation, and the study was approved by the Ethics Committee of the School of Medicine (University of Santiago de Compostela).

The weight of 7 of these children was equal or lower or below P3, and in 3 of them there was a clear malnourishment (Body Mass Index $<14 \mathrm{~kg} / \mathrm{m}^{2}$ ). All of them were in pre pubertal status (Tanner I-III). Two children had received prophylactic cranial irradiation due to brain tumors, 5 and 3 years before the study. One of the children had suffered a traumatic brain injury 3 years before. 12 children had been considered to have Short Family stature. In 4 of the cases existed low weight at birth, while the remaining children had been considered to present Constitutional Growth delay. All children had been previously studied for their GH deficiency or insufficiency: growth velocity, bone age, classical provocative tests for $\mathrm{GH}$ secretion (i.e. clonidine, insulin hypoglycaemia and propranolol plus exercise), plasma Insulin Growth Factor-I (IGF-I) analysis, and analysis of the spontaneous pattern of nocturnal GH secretion (area under the $\mathrm{GH}$ curve [AUC] in blood samples drawn at 20-minutes intervals during the night.

Studies for analyzing the $\mathrm{GH}$ response to $\mathrm{CLO}+\mathrm{GHRH}$ commenced at $09.00 \mathrm{~h}$ after an overnight fast and bed rest and thirty minutes after the insertion of an indwelling catheter for blood withdrawal in a forearm vein. The study consisted of administering CLO (Catapresan, Boehringer Ingelheim, Spain) orally, $150 \mathrm{\mu g} / \mathrm{m}^{2}$ at time 0 minutes, followed by the 
administration of GHRH (GRF 1-29, Serono, Spain) as an intravenous bolus $(1 \mu \mathrm{g} / \mathrm{kg})$ at time 60 minutes. Three days later, an additional control for short children was performed, administering placebo at time 0 , and then GHRH 60 minutes later.

\section{Control children}

In 20 age-matched normal stature children (14 boys and 6 girls) the $\mathrm{GH}$ responses to CLO plus GHRH were analyzed, as in short stature children, after evaluating the growth velocity during six months and the bone age (X-ray of the left wrist).

In both groups of children, blood samples for $\mathrm{GH}$ analysis were drawn at 0 and 60 minutes and at 15 minute intervals for one hour following GHRH administration. Plasma $\mathrm{GH}$ was measured by radioimmunoassay using a commercial kit (BioMerieux, France). The mean intra-assay coefficient of variation was $5.7,3.2$ and $4.3 \%$ at mean $\mathrm{GH}$ concentrations of $1.5,10$ and $22 \mathrm{ng} / \mathrm{ml}$ respectively. To avoid interassay variations, all samples were run in the same assay, after being stored at -4 으 until assayed.

\section{Statistics}

To establish the normal range of GH peaks in response to CLO +GRF in normal children a multivariate regression analysis was performed. The non-parametric Wilcoxon's test was used to compare the results obtained in the CLO+GRF test in both group of children. A value of $\mathrm{P}<0.05$ was considered to be statistically significant. Data are presented as Mean \pm SEM, unless other parameters are indicated.

\section{Results}

\section{Short stature children}

$56 \%$ of these children showed a $\mathrm{GH}$ response to $\mathrm{CLO}<10$ $\mathrm{ng} / \mathrm{ml}$, the same happened in $36 \%$ of children after being stimulated with propranolol plus exercise, and in 6 of the 7 patients studied with the insulin-induced hypoglycemia (Table 1). However, in all but 6 children, indices of total and pulsatile nocturnal GH release appeared to be normal; plasma IGF-I values were below normal limits for age in 18 of them. Mean \pm SEM plasma IGF-I was $51 \pm 7.1 \mathrm{ng} / \mathrm{ml}$ (normal range for the age: $47-315 \mathrm{ng} / \mathrm{ml})$. Mean \pm SEM growth velocity was $3.7 \pm 0.9 \mathrm{~cm} /$ yearr. Thyroid hormones and cortisol were in normal values (data not shown).

GHRH administration 60 minutes after placebo, induced a GH peak of $19.5 \pm 15.7 \mathrm{ng} / \mathrm{ml}$. This value was significantly $(P<0.01)$ increased when GHRH was administered 60 minutes after CLO administration: $42.2 \pm 19$, although two children did not show any significant change in the $\mathrm{GH}$ peak after $\mathrm{CLO}+\mathrm{CHRH}$ challenge (GH peak $<10 \mathrm{ng} / \mathrm{ml}$ ).

Table 1: Number of positive $(+,>10 \mathrm{ng} / \mathrm{ml})$ or negative $(-,<10 \mathrm{ng} / \mathrm{ml}) \mathrm{GH}$ peaks in response to different provocative tests performed in Short Children. Note that this group of children has been subdivided into five different groups according to the individual deviations between the theoretically calculated GH peak response to CLO+GHRH and the real value obtained. (See Table 2 for a better understanding of this concept). Note the great variability in the responses to different stimuli in each subgroup.

\begin{tabular}{|c|c|c|c|c|c|c|}
\hline Subgroup & $n$ & $P+E$ & CLO & $\mathbf{I H}$ & GHRH & $\mathrm{CLO}+\mathrm{GHRH}$ \\
\hline 1 & 6 & $+3,-3$ & $+0,-6$ & $+0,-6$ & $+2,-4$ & $+4,-2$ \\
\hline 2 & 5 & $+3,-2$ & $+4,-1$ & $\mathrm{NP}$ & $+3,-2$ & 5 \\
\hline 3 & 5 & $+3,-1$ & $+2,-2$ & $\mathrm{NP}$ & $+3,-1$ & 5 \\
\hline 4 & 5 & $+4,-1$ & $+3,-2$ & $\mathrm{NP}$ & $+3,-2$ & 5 \\
\hline 5 & 3 & $+1,-1$ & $+1,-2$ & 1 & 3 & 3 \\
\hline
\end{tabular}

\section{Control children}

Pre-treatment with $\mathrm{CLO}$ led to $\mathrm{GH}$ response to $\mathrm{GHRH}$ of $41.6 \pm 3.5 \mathrm{ng} / \mathrm{ml}$, a peak value not significantly different to that obtained in short stature children after CLO+GHRH test. There was a significant positive correlation between the amplitude of $\mathrm{GH}$ response and both chronological and bone age $(R=0.832$; $\mathrm{F}=37.6 ; \mathrm{P}=0.001$ ), as established by a multiple regression. This analysis gave origin to an equation: $y=a+b \times B A+c \times C A$, where $\mathrm{y}=\mathrm{GH}$ peak, $\mathrm{BA}=$ bone age, $\mathrm{CA}=$ chronological age, and $\mathrm{a}, \mathrm{b}$ and $\mathrm{c}$ are constants obtained. Values of $a, b$ and $c$ can vary according to the number of subjects in the normal population analyzed. This positive correlation was also observed between $\mathrm{GH}$ peaks and the bone age/growth velocity ratio in this group of normal children. Therefore, this equation would allow establishing the value of GH peak that theoretically should be obtained after CLO + GHRH challenge in a normal stature child.

To confirm the validity of CLO plus GHRH test to establish GHdeficient or insufficient states and to differentiate among their causes, we calculated the theoretical GH responses to this test in short children according to the equation above described. There was a deviation between theoretical values of $\mathrm{GH}$ peaks which should be obtained with this equation and the real $\mathrm{GH}$ peak values obtained after CLO plus GHRH. The percentage of the deviation between theoretical values $(T)$ and real values (R) ranged between $-435 \%$ and $+41 \%$ (Table 2 ). Responses between the $-20 \%$ to $+20 \%$ range were considered to be normal, as they fitted between one standard deviation from the mean in the group of normal children. Plotting these responses (\% DT-R) 
against the standard deviation of the mean of the bone age to growth velocity ratio in normal children, five populations were showed to exist: 1) Low response and low growth velocity for bone age; 2) Low response and normal growth velocity for bone age; 3) Normal response and low growth velocity for bone age; 4) Normal response with normal growth velocity for bone age; 5) High response with low growth velocity for bone age. These data are shown in Figure 1.

Figure 1

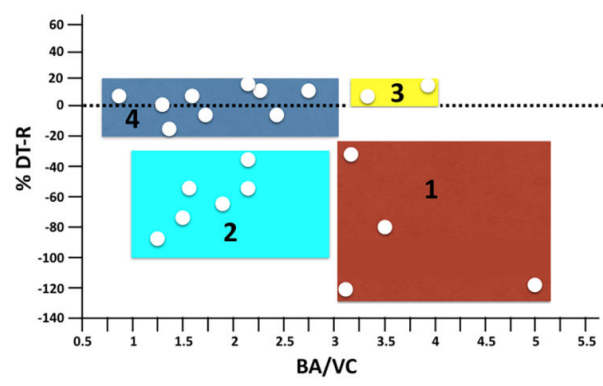

Figure 1: Differential diagnosis of GH-deficiency according to the percentage of deviation between the theoretical GH peak induced by $\mathrm{CLO}+\mathrm{GHRH}$ challenge and the real peak obtained after this stimulation (y axis, \% DT-R) in short stature children, plotted against the deviation of the bone age to growth velocity ratio in normal children ( $x$ axis, BA/VC). \% DT-R values comprised between -20 and 20 are considered as normal responses (see the text), while values over 20 are considered as high responses and values below -20 are considered as low responses. 1 (red rectangle): indicates pituitary GH deficiency or insufficiency. 2 (light blue rectangle) indicates

Neurosecretory Dysfunction. 3 (yellow rectangle): indicates Short Family stature. 4 (dark blue rectangle): indicates Constitutional Growth Delay. In this Figure the subgroup 5 is not represented because of the low body mass index and deficient nutritional conditions existing in the three children of this subgroup.

\section{Discussion}

According to our results it seems to be clear that the varied situations of GH-deficient or insufficiency may be differentiated by the combined administration of an alpha-2-adrenergic agonist, such as clonidine, and GHRH. This test both analyzes the functionality of the hypothalamic zones involved in $\mathrm{GH}$ control, and directly evaluates the secretory integrity of somatotropes. Therefore, no false negative responses are expected to occur. Moreover, it minimizes, at high $\mathrm{GH}$ levels, the variability in $\mathrm{GH}$ responses to $\mathrm{GHRH}$, thus allowing its use in the treatment of short children having a hypothalamic dysfunction responsible for their diminished linear growth.

Therefore, it seems that the CLO plus GHRH test has a strong and an unique value to allow better differentiation among the diverse GH-deficient states; therefore it might optimize the decision about which children must be treated and when the treatment must start.

Diagnosis of GHD is based on auxologic, clinical and hormonal criteria [27-29]. The latter is mainly related to the $\mathrm{GH}$ response to provocative tests. However, until now, all of the known provocative tests for $\mathrm{GH}$ secretion usually lead to a number of false negative results. This is the main reason by which Regulatory Authorities and $\mathrm{GH}$-Committees established that for improving the validity of the biochemical diagnosis of GHD two different provocative stimuli have to be performed. Nevertheless, results here presented (Table 1) are a clear demonstration that a same child may respond negatively or positively to two different challenges. Interestingly, in that Table 1 it could be seen that none of the children of the subgroup 1 responded to the Insulin-induced hypoglycaemia, a test considered to be the "gold standard test", while four of them showed a positive response to $\mathrm{CLO}+\mathrm{GHRH}$, and even in two of these patients a response to $\mathrm{GHRH}$ given alone could be observed. This is quite surprising since it is well known that hypoglycaemia induces an adrenergic response; in fact catecholamines form part of the group of counter regulatory hormones that oppose the action of insulin, and they also act by blocking hypothalamic somatostatin release [18], then allowing the endogenous GHRH to be released $[10,11]$. Therefore a positive response should be observed in these cases, as it happened in four of them when they were tested with CLO + GHRH or in three of these children after being stimulated with propranolol plus exercise (Table 1). The only feasible explanation for these divergences is the phase of HSR at which they had been tested [12], not considered when the stimulation was performed. Another possibility, such as the lack of hypothalamic GHRH production, has to be discarded since in this subgroup 1 there was a positive response to propranolol plus exercise in three cases, and in two patients challenged with GHRH alone (Table 1). Since GHRH induces the pituitary synthesis of $\mathrm{GH}$ $[10,11]$, no response to exogenous GHRH administration should be observed in these two patients given that no pituitary stores of $\mathrm{GH}$ could exist. These divergences among the different tests carried out were also observed in the other subgroups of children, with the unique exception of CLO+GHRH test for which a positive $\mathrm{GH}$ response was observed in all cases (Table 1 ).

Apart of this, the cut-off value to establish whether a patient suffers GH-deficiency is quite arbitrary for most of the tests usually utilized and it has been changing during years. In addition, classical provocative tests are unable to characterize the various $\mathrm{GH}$-deficient states. Therefore, the utility of these tests continues to be a matter of controversy [30]. In fact, more than 30 different stimuli for analyzing $\mathrm{GH}$ secretion have been already described [31]. As a clear consequence of these controversies a survey carried out in USA among paediatric 
endocrinologists concluded that, in general, main indications to treat a paediatric patient with $\mathrm{GH}$ are: poor growth velocity, poor target height and low plasma IGF-I levels [32].

Table 2: Percentage of deviation (\%DT-R) between the theoretically calculated GH peak response to CLO+GHRH challenge (according to the equation $\mathrm{y}=\mathrm{a}+\mathrm{b} \times \mathrm{BA}+\mathrm{c} \times \mathrm{CA})$ and the GH peak obtained after this stimulation in each subgroup of Short Children. Note that the highest deviation was observed in the subgroup 1. Results are shown as the Mean $\pm \mathrm{SEM}$, but the range of deviations oscillated between $-435 \%$ and $+41 \%$.

\begin{tabular}{|c|c|c|c|c|c|c|}
\hline Subgroup & $\mathbf{n}$ & \%DT-R & GV & MCGH & CA & BA \\
\hline 1 & 6 & $211 \pm 163$ & $2.8 \pm 0.06$ & $4.1 \pm 2.1$ & $10.9 \pm 2.1$ & $8.3 \pm 2$ \\
\hline 2 & 5 & $-69 \pm 36$ & $4.5 \pm 0.4$ & $5.2 \pm 0.9$ & $11 \pm 1.3$ & $8.1 \pm 1.7$ \\
\hline 3 & 5 & $9 \pm 6.2$ & $3.6 \pm 0.4$ & $4.9 \pm 2$ & $8.4 \pm 1.2$ & $5.9 \pm 1.7$ \\
\hline 4 & 5 & $4 \pm 9$ & $4.4 \pm 1$ & $5.9 \pm 1$ & $11 \pm 2.2$ & $8.4 \pm 3$ \\
\hline 5 & 3 & $36 \pm 5$ & $3.3 \pm 0.3$ & $7.8 \pm 1.8$ & $8.3 \pm 1.2$ & $4.6 \pm 1.5$ \\
\hline
\end{tabular}

$\mathrm{GV}=$ Growth velocity $(\mathrm{cm} /$ year). $\mathrm{MCGH}=$ Mean $\pm \mathrm{SEM}$ plasma $\mathrm{GH}$ concentrations $(\mathrm{ng} / \mathrm{ml})$ during a nocturnal period of sampling. $\mathrm{CA}=\mathrm{Chronological}$ age $(\mathrm{years}) . \mathrm{BA}=\mathrm{Bone}$ age (years).

That is, tests of $\mathrm{GH}$ secretion in short stature children are not considered priorities for commencing a treatment with the hormone. At this point and although it is not the objective of this study, low plasma IGF-I values do not necessarily reflect GHdeficient secretion. As we recently published, the hepatic expression of IGF-I is strongly conditionated by the intracellular metabolism of glucose [33], therefore poor nutritional conditions may lead to low plasma levels of this factor despite of normal or increased $\mathrm{GH}$ secretion, as it happens in Anorexia Nervosa patients [34]. It can occur too in children with strong spasticity due to brain injuries. The high avidity of spastic muscles for glucose may lead to low IGF-I production by the liver.

In summary, in this study carried out in 1993, we demonstrated that the test $\mathrm{CLO}+\mathrm{GHRH}$ is useful for analyzing $\mathrm{GH}$ a posible $\mathrm{GH}$-deficiency in short stature children and establishing the most probable causes of it. According to our results, the different subgroups of short children analyzed could be classified into other 5 groups (Figure 1): children from Group 1 are $\mathrm{GH}$-deficient, from pituitary origin in two of them, and hypothalamic (neurosecretory dysfunction) in the other two. While the first two would to be treated with $\mathrm{GH}$, the other two would benefit from a treatment with $\mathrm{CLO}+\mathrm{GHRH}$. Children from Group 2 suffer a Neurosecretory Dysfunction, therefore they also would need $\mathrm{GH}$ treatment although they could also be treated with $\mathrm{CLO}+\mathrm{GHRH}$. In Group 3 we placed 2 children with Short Family stature; most likely GH treatment or CLO+GHRH would increase their growth velocity and height. The 9 children in Group 4 appear to have Constitutional Growth Delay; therefore no GH therapy would be needed in this group, although gonadal function should be studied in them. Lastly, children from Group 5 were malnourished; hence pre-treatment with clonidine did not significantly enhance the $\mathrm{GH}$ response to GHRH.

In summary, the combined test with clonidine and GHRH allows the differentiation among diverse $\mathrm{GH}$-deficient states. Pre-treatment with CLO places the subjects in a similar basal state thus eliminating interferences due to the hypothalamicsomatotroph rhythm [12]. Therefore, $\mathrm{GH}$ responses would be a real expression of the pituitary reserve of $\mathrm{GH}$, indicating the functionality of the hypothalamus-somatotrope axis. Hence, this test does not give false negative responses and facilitates the differential diagnosis of $\mathrm{GH}$-deficiency without the need for other provocative tests or the analysis of spontaneous $\mathrm{GH}$ secretion. In addition, some children growing below P3 and showing a positive response to $\mathrm{CLO}+\mathrm{GHRH}$, independently of the degree of deviation from theoretically calculated values might benefit from a treatment with both compounds.

For carrying out the $\mathrm{CLO}+\mathrm{GHRH}$ test and analyzing the $\mathrm{GH}$ responses in short children, a normal population of different prepubertal ages should be studied before to establish the equation $y=a+b \times B A \times c \times C A$, which would serve as reference for the normality or not of the GH peak. Even more, the normal responses to this test should be separately analyzed in boys and girls. Unfortunately, GHRH is no longer available in many countries (including Spain). Moreover, since we developed this test 24 years ago, a number of factors that may interfere with the $\mathrm{GH}$ responses have been discovered. Among them, the intricate relationships between auto/paracrine effects of $\mathrm{GH}, \mathrm{SS}$ and GHRH on its own secretion, the pituitary production of IGF-I, the role of the gastric hormone Ghrelin, or the release of leptin by adipocytes, nutritional conditions, stress, etc. [11]. In addition, many recent data indicate that the aging-suppressor gene Klotho is a direct regulator of GH secretion [35]. However, we still think that the $\mathrm{CLO}+\mathrm{GHRH}$ test is a clear reproducible and safe test for analyzing possible states of GH-deficiency and its causes, even in adulthood [36].

\section{Conflict of Interests}

No conflicts of interest exist. 


\section{Acknowledgements}

Auxological and clinical data were obtained from clinical records provided by Dr. A. Fernández Mariño (Vigo, Spain). GH tests and hormonal assays were performed in the Laboratory of Special Biochemistry and Hormones of University Hospital of Santiago de Compostela. GHRH was freely provided by Serono Inc. (Madrid, Spain).

\section{References}

1. Rivier J, Spiess J, Thorner M, Vale W (1982) Characterization of a growth hormone-releasing factor from a human pancreatic islet tumour. Nature 300: 276-278.

2. Guillemin R, Brazeau P, Bohlen P, Esch F, Ling N, et al. (1982) Growth hormone releasing factor from a pancreatic tumor that caused acromegaly. Science 218: 585-587.

3. Thorner MO, Rivier J, Spiess J, Borges JL, Vance ML, et al. (1983) Human pancreatic growth-hormone-releasing factor selectively stimulates growth hormone secretion in man. Lancet 1: 24-28.

4. Vance ML, Borges JL, Kaiser DL, Evans WS, Furlanetto R, et al. (1984) Human pancreatic tumor growth hormone-releasing factor: dose-response relationships in normal man. J Clin Endocrinol Metab 58: 838-844.

5. Rogol AD, Blizzard RM, Johanson AJ, Furlanetto RW, Evans WS, et al. (1984) Growth hormone release in response to human pancreatic tumor growth hormone-releasing hormone-40 in children with short stature. J Clin Endocrinol Metab 59: 580-586.

6. Evans WS, Vance ML, Kaiser DL, Sellers RP, Borges JL, et al. (1985) Effects of intravenous, subcutaneous, and intranasal administration of growth hormone (GH)-releasing hormone-40 on serum GH concentrations in normal men. J Clin Endocrinol Metab 61: 846-850.

7. Thorner MO, Rogol AD, Blizzard RM, Klingensmith GJ, Najjar J, et al. (1988) Acceleration of growth rate in growth hormonedeficient children treated with human growth hormone-releasing hormone. Pediatr Res 24: 145-151.

8. Rochiccioli PE, Tauber MT, Coude FX, Arnone M, Morre M, et al. (1987) Results of 1-year growth hormone (GH)-releasing hormone-(1-44) treatment on growth, somatomedin-C, and 24hour GH secretion in six children with partial GH deficiency. J Clin Endocrinol Metab 65: 268-274.

9. Low LC, Wang C, Cheung PT, Ho P, Lam KS, et al. (1988) Long term pulsatile growth hormone (GH)-releasing hormone therapy in children with GH deficiency. J Clin Endocrinol Metab 66: 611-617.

10. Devesa J, Lima L, Tresguerres JA (1992) Neuroendocrine control of growth hormone secretion in humans. Trends Endocrinol Metab 3: 175-183.

11. Steyn FJ, Tolle V, Chen C, Epelbaum J (2016) Neuroendocrine Regulation of Growth Hormone Secretion. Compr Physiol 6: 687-735.

12. Devesa J, Lima L, Lois N, Fraga C, Lechuga MJ, et al. (1989) Reasons for the variability in growth hormone $(\mathrm{GH})$ responses to $\mathrm{GHRH}$ challenge: the endogenous hypothalamic-somatotroph rhythm (HSR). Clin Endocrinol (Oxf) 30: 367-377.

13. Frasier SD (1974) A preview of growth hormone stimulation tests in children. Pediatrics 53: 929-937.
14. Gil-Ad I, Topper E, Laron Z (1979) Oral clonidine as a growth hormone stimulation test. Lancet 2: 278-279.

15. Plotnick LP, Lee PA, Migeon CJ, Kowarski AA (1979) Comparison of physiological and pharmacological tests of growth hormone function in children with short stature. J Clin Endocrinol Metab 48: 811-815.

16. Underwood LE (1985) Normal and Aberrant Growth. In: Williams Textbook of Endocrinology. W.B. Saunders Company, Philadelphia.

17. Grossman A, Savage MO, Blacklay A, Ross RM, Plowman PN, et al. (1985) The use of growth hormone-releasing hormone in the diagnosis and treatment of short stature. Horm Res 22: 52-57.

18. Devesa J, Arce V, Lois N, Tresguerres JA, Lima L (1990) Alpha 2 adrenergic agonism enhances the growth hormone $(\mathrm{GH})$ response to GH-releasing hormone through an inhibition of hypothalamic somatostatin release in normal men. J Clin Endocrinol Metab 71: 1581-1588.

19. Arce V, Cella SG, Loche S, Ghigo E, Devesa J, et al. (1990) Synergistic effect of growth hormone-releasing hormone (GHRH) and clonidine in stimulating $\mathrm{GH}$ release in young and old dogs. Brain Res 537: 359-362.

20. Lima L, Arce V, Tresguerres JAF, Devesa J (1993) Clonidine potentiates Growth Hormone (GH)-Responsiveness to $\mathrm{GH}$ Releasing Hormone (GHRH) in aged male rats: Evidence for Alpha2-adrenergic-mediated Inhibition of Hypothalamic Somatostatin Release. Neuroendocrinology 57:1155-1160.

21. Mazza E, Ghigo E, Goffi S, Procopio M, Imperiale E, et al. (1989) Effect of the potentiation of cholinergic activity on the variability in individual GH response to $\mathrm{GH}$-releasing hormone. J Endocrinol Invest 12: 795-798.

22. Davis TM, Burrin JM, Bloom SR (1987) Growth hormone (GH) release in response to $\mathrm{GH}$-releasing hormone in man is 3 -fold enhanced by galanin. J Clin Endocrinol Metab 65: 1248-1252.

23. Chatterjee VK, Ball JA, Proby C, Burrin JM, Bloom SR (1988) Galanin abolishes the inhibitory effect of cholinergic blockade on growth hormone-releasing hormone-induced secretion of growth hormone in man. J Endocrinol 116: 1-2.

24. Ghigo E, Imperiale E, Boffano GM, Mazza E, Bellone J, et al. (1990) A new test for the diagnosis of growth hormone deficiency due to primary pituitary impairment: combined administration of pyridostigmine and growth hormone-releasing hormone. J Endocrinol Invest 13: 307-316.

25. Devesa J, Diaz MJ, Tresguerres JA, Arce V, Lima L (1991) Evidence that alpha 2-adrenergic pathways play a major role in growth hormone $(\mathrm{GH})$ neuroregulation: alpha 2-adrenergic agonism counteracts the inhibitory effect of muscarinic cholinergic receptor blockade on the $\mathrm{GH}$ response to $\mathrm{GH}$-releasing hormone, while alpha 2-adrenergic blockade diminishes the potentiating effect of increased cholinergic tone on such stimulation in normal men. J Clin Endocrinol Metab 73: 251-256.

26. Reiter EO, Morris AH, Biggs DE (1988) Modulation of GHRHinduced Growth Hormone release by an Alpha-Adrenergic agonist and Hypoglycemia. J Pediatr Endocrinol Metab 3: 21-26.

27. RABEN MS (1958) Treatment of a pituitary dwarf with human growth hormone. J Clin Endocrinol Metab 18: 901-903.

28. Cohen P, Rogol AD, Deal CL, Saenger P, Reiter EO, et al. (2008) Consensus statement on the diagnosis and treatment of children with idiopatic short stature: a summary of the growth hormone research society, the Lawson Wilkins paediatric endocrine society, 
and the European society for paediatric endocrinology workshop. J Clin Endocrinol Metab 93: 4210-4217.

29. Collett-Solberg PF (2011) Update in growth hormone therapy in children. J Clin Endocrinol Metab 96: 573-579.

30. Carrascosa A, Audi L, Fernandez-Cancio M, Yeste D, Gussinye M, et al. (2011) Growth hormone secretory status evaluated by growth hormone peak after two pharma- cological growth hormone release stimuli did not significantly influence the two-year catchup growth induced by growth hormone therapy in 318 prepubertal short children with idiopatic growth retardation. Horm Res Paediatr 75: 106-114.

31. Sizonenko PC, Clayton PE, Cohen P, Hintz RL, Tanaka T, et al. (2001) Diagnosis and management of growth hormone deficiency in childhood and adolescence. Part 1: diagnosis of growth hormone deficiency. Growth Horm IGF Res 11: 137-165.

32. Hardin DS, Woo J, Butsch R, Huett B (2007) Current prescribing practices ad opinions about growth hormone therapy: results of a nationwide survey of paediatric endocrinologists. Clin Endocrinol (Oxf) 66: 85-94.

33. Devesa J, Almengló C, Devesa P (2016) Multiple effects of Growth Hormone in the body: Is it really the hormone for growth? Clin Med Insights Endocrinol Diabetes 9: 47-71.

34. Casanueva FF, Borras CG, Burguera B, Lima L, Muruais C, et al. (1987) Growth hormone and prolactin secretion after growth hormone-releasing hormone administration, in anorexia nervosa patients, normal controls and tamoxifen-pretreated volunteers. Clin Endocrinol (Oxf) 27: 517-523.

35. Rubinek T, Modan-Moses D (2016) Klotho and the Growth Hormone/Insulin-Like Growth Factor 1 Axis: Novel Insights into Complex Interactions. Vitam Horm 101: 85-118.

36. Lima L, Arce V, Díaz MJ, Tresguerres JA, Devesa J (1991) Clonidine pretreatment modifies the growth hormone secretory pattern induced by short-term continuous GRF infusion in normal men. Clin Endocrinol (Oxf) 35: 129-135. 